\title{
Posterior parietal cortex and long-term memory: some data from laboratory animals
}

\author{
Jociane C. Myskiw ${ }^{2}$ and Iván Izquierdo ${ }^{1 *}$ \\ Centro de Memoria, Instituto do Cérebro, Pontifical Catholic University of Rio Grande do Sul, Porto Alegre, RS, Brazil \\ 2 Instituto Nacional de Neurociência Translacional, Conselho Nacional de Desenvolvimento Científico e Tecnológico (CNPq), Porto Alegre, RS, Brazil
}

Edited by:

David J. Bucci, Dartmouth College, USA

Reviewed by:

Barry Setlow, University of

Florida, USA

Jeffrey Long, NIH, USA

*Correspondence:

Iván Izquierdo, Centro de Memoria,

Instituto do Cérebro, Pontifical

Catholic University of Rio Grande do

Sul, Porto Alegre, RS 90035-003,

Brazil.

e-mail: izquier@terra.com.br
The posterior parietal cortex (PPC) was long viewed as just involved in the perception of spatial relationships between the body and its surroundings and of movements related to them. In recent years the PPC has been shown to participate in many other cognitive processes, among which working memory and the consolidation and retrieval of episodic memory. The neurotransmitter and other molecular processes involved have been determined to a degree in rodents. More research will no doubt determine the extent to which these findings can be extrapolated to primates, including humans. In these there appears to be a paradox: imaging studies strongly suggest an important participation of the PPC in episodic memory, whereas lesion studies are much less suggestive, let alone conclusive. The data on the participation of the PPC in episodic memory so far do not permit any conclusion as to what aspect of consolidation and retrieval it handles in addition to those dealt with by the hippocampus and basolateral amygdala, if any.

Keywords: posterior parietal cortex, memory consolidation, memory retrieval, episodic memory, working memory

\section{INTRODUCTION}

The posterior parietal cortex (PPC) is involved in a variety of mental and neural processes, as other articles in this issue attest. In recent years, it was found to play a key role both in working memory, and in the making and retrieval of episodic memory. The role of the PPC in memory was viewed as untraditional by Olson and Berryhill in 2009.

\section{WORKING MEMORY}

There is strong and variegated evidence for a role of the PPC in working memory (see other articles in this volume). Most authors propose a role [e.g., (Rawley and Constantinidis, 2009)], as part of an extensive working memory brain circuit that involves dopaminergic mechanisms in regions of the prefrontal cortex (Goldman-Rakic, 1991; Izquierdo et al., 1998) and hippocampus (Izquierdo et al., 1998; Aujla and Beninger, 2001) and cholinergic muscarinic (Ingles et al., 1993; Izquierdo et al., 1998), and nicotinic receptors in the basolateral amygdala (Barros et al., 2005). Actually there are many types of working memory: for example, in music, working memory for melody activates the PPC whereas working memory for rhythm activates the cerebellum and the right insula (Jerde et al., 2011), and the prefrontal and PPC contributions to spatial working memory are different (Curtis, 2006). The role of the PPC in working and long-term memory of spatial tasks is differentially affected by reversible inhibition of the PPC by the local infusion of lidocaine (Espina-Marchant et al., 2009).

Working memory is used both in order to make and to retrieve memories. It is well-known to fail in schizophrenia (Lepage et al., 2010; Kang et al., 2011) and to decline with old age (Elliott and Dolan, 1998) along with the development of an asymmetry of parietal cortex activation (Otsuka et al., 2008).
There have been several important functional studies of working memory in animal models in recent years. Very few studies have tested effects of drugs on working memory given by microinjection into the PPC in rats or mice (Izquierdo et al., 1998), as is usually done in investigations of the role of other brain regions in this type of memory, or any other for that matter (Izquierdo et al., 2006, 2007). Our group has reported on the effect of well-known neurotransmitter antagonists on working memory measured as immediate memory in the rat (Izquierdo et al., 1998). Immediate memory is recognized as a measure of working memory (Goldman-Rakic, 1991; see Jacobsen, 1936).

In the study reviewed here (Izquierdo et al., 1998), rats were implanted with chronic bilateral cannulae in the hippocampus, entorhinal, anterolateral prefrontal, or PPC and were submitted to a one-trial step-down inhibitory avoidance task, by far the task most widely used task in memory studies over the past 60 or so years (McGaugh, 1966, 2000; Gold, 1986; Izquierdo et al., 2007). The animals were given various treatments (the cholinergic muscarinic receptor blocker, scopolamine $2.5 \mu \mathrm{g}$, the glutamate NMDA antagonist, aminophosphonopentanoic acid (AP5) $5 \mu \mathrm{g}$, the glutamate AMPA receptor antagonist, CNQX $0.5 \mu \mathrm{g}$, the $\mathrm{GABA}_{\mathrm{A}}$ receptor agonist muscimol $0.5 \mu \mathrm{g}$, or the dopamine D1 receptor antagonist, $\mathrm{SCH} 233900,0.5 \mu \mathrm{g}$ ) into the structures reached by the cannulae $5 \mathrm{~min}$ before training. The doses were those usual in brain microinjection studies [see (Izquierdo et al., 1998, 2007) for references]. During training, the animals were gently placed on a $3 \mathrm{~cm}$-high, $25 \mathrm{~cm}$-long platform facing a metallic grid and left to explore the apparatus freely. In 5-15s all of them eventually stepped down onto the grid. When they had placed their four paws on it, they received a mild $(0.3 \mathrm{~mA})$, very brief $(2 \mathrm{~s})$ footshock, were immediately withdrawn from the apparatus, and were placed again on the platform, a procedure that 
took less than $5 \mathrm{~s}$. Their step-down latency was measured again, as an estimation of immediate (working) memory. The drugs were given 5 min before training. They had different effects in the different structures; all except AP5 were able to markedly inhibit immediate memory when given into PPC or hippocampus, suggesting that muscarinic cholinergic receptors, dopamine D1 receptors, and AMPA but not NMDA glutamate receptors play a role in working memory in these two areas (Izquierdo et al., 1998). The D1 antagonist studied was SCH23390, the AMPA receptor antagonist was CNQX, and the NMDA blocker was AP5. In the anterolateral prefrontal cortex, long known to play a role in working memory (Goldman-Rakic, 1991; Izquierdo et al., 1998), SCH23390 also hindered working memory. The data suggest that the PPC is involved in the processing of working memory, measured as immediate memory, through biochemical processes not very different from those used by other brain structures traditionally known to regulate that form of memory, like anterolateral prefrontal cortex, hippocampus, and amygdala (Goldman-Rakic, 1991; Izquierdo et al., 1998, 2007; Aujla and Beninger, 2001). In the posterior parietal area these processes apparently involve glutamate AMPA but not NMDA glutamate receptors, D1 dopaminergic enhancement, and GABAergic down regulation.

As mentioned, probably the PPC plays its role in working memory in connection with that of the hippocampus (Izquierdo et al., 1998; Aujla and Beninger, 2001) and basolateral amygdala (Ingles et al., 1993; Barros et al., 2005), two structures to which it is linked by afferent and efferent pathways that relay in the entorhinal cortex (Ding et al., 2000; Izquierdo et al., 2006).

A number of studies, particularly lesion studies (Pinto-Hamuy et al., 2004; Espina-Marchant et al., 2009; McVea and Pearson, 2009) have shown a role of the PPC in the long-term consequences of working memory. Since the lesions antecede the behavioral procedures it is difficult to conclude whether their deleterious effect is on the working memory itself or on its transfer to short- or long-term memory stores. In electrophysiological studies on the firing of posterior parietal cells during the walking of cats through obstacles (McVea and Pearson, 2009; McVea et al., 2009), the information thus generated can then be kept during minutes for on-going walking (McVea et al., 2009) or for much longer times, when walking again through that path much later (McVea and Pearson, 2009). Such long-lasting transfers of working memory information must participate in the engagement of the PPC with the hippocampus in the learning of spatial navigation (Whitlock et al., 2008) or ambulation (McVea et al., 2009), whose memory can of course last for many days or more.

Constantinidis and his associates (Constantinidis, 2006; Curtis, 2006; Joelving et al., 2007; Rawley and Constantinidis, 2009) have studied extensively the firing of PPC neurons in situations that clearly (Constantinidis and Steinmetz, 1996) or most likely (Curtis, 2006; Joelving et al., 2007) involve working memory. Among their many key findings, one is particularly intriguing: the decreased range in the $5-10 \mathrm{~Hz}$ frequency range of such firing during presentations of visual stimuli in a working memory situation relative to control periods (Curtis, 2006). This probably resulted from the longer refractory periods in the former and engagement of local inhibitory circuitry; as the authors say, this has also been observed in prefrontal regions that are involved in working memory processing. For other relation between prefrontal and parietal participations in this processing, [see (Quintana and Fuster, 1999; Chafee and Goldman-Rakic, 2000; Curtis, 2006)].

A number of authors suggest that the PPC, long known to be crucially involved in attention (Constantinidis, 2006; Bucci, 2009), is in reality an interface between attention and learning (Bucci, 2009), and/or part of a larger network involved in attention which includes the dorsocentral striatum, the lateral posterior indeed thalamic nucleus and other brain regions (Reep and Corwin, 2009). The distinction between the mechanisms of attention and working memory is subtle (Constantinidis, 2006; Bucci, 2009; Reep and Corwin, 2009), and probably both are different depending on the part of the brain examined. For example, recording experiments in monkeys show that attention is processed by signals derived from task demands ("top-down") in the prefrontal cortex, but by signals from salient stimuli ("bottomup") in the parietal cortex (Buschman and Miller, 2007). There have been studies and speculations on the intersection of attention and memory, which suggest that the PPC may serve to filter distractors (Friedman-Hill et al., 2003) and maintains or shifts internal attention among the representation of items in working memory (Berryhill et al., 2011).

\section{LONG-TERM MEMORY: ENCODING AND/OR CONSOLIDATION}

Encoding is the first step in creating a memory. It involves the perception of sensory signals and their after effects. Immediately thereafter there is consolidation, which consists of the translation of those perceptions into brain language [postsynaptic transmitter effects and action potentials] (Delgado-García, 2011) and their formatting into memory files. Memory is a brain function that comprises encoding, consolidation, persistence, maintenance, and retrieval.

Participation of the PPC in long-term episodic memory began to be realized rather recently and has so far been specifically studied by few groups (Rogers and Kesner, 2007; Berryhill et al., 2007, 2010a,b; Keene and Bucci, 2008; Hutchinson et al., 2009; Drowos et al., 2010). Some of this work has involved classic animal (Compton et al., 1994; Rogers and Kesner, 2007; Berryhill et al., 2007; Keene and Bucci, 2008) or human (Berryhill et al., 2010a,b; Drowos et al., 2010) lesion studies, and typical posttraining microinjection and assay techniques (Zanatta et al., 1996; Ardenghi et al., 1997; Izquierdo et al., 1997; Barros et al., 1998; Schröder et al., 2000; Luft et al., 2004; Bonini et al., 2005; Alonso et al., 2005) or post-training lesion studies (Rossato et al., 2004).

The formation of long-term episodic memories is not to be confused with the transfer of working memory to long-term stores (Richmond et al., 2011). The former relies on a complex sequence of biochemical events in the hippocampus (Izquierdo et al., 2007) that are linked to, and probably involve longterm potentiation (Delgado-García and Gruart, 2006; Whitlock et al., 2006, 2008; Clarke et al., 2010); related but different changes occur in basolateral amygdala, entorhinal cortex, and PPC (Jiménez-Díaz et al., 2006; Izquierdo et al., 2007). The transfer of working memory to long-term stores uses as yet unknown 
mechanisms that probably occur mainly in the PPC and may maintain or shift the representation of items in working memory (Berryhill et al., 2011).

The contribution of the parietal cortex to episodic memory in higher primates including humans is viewed by many as a puzzle (Cabeza et al., 2008): whereas an activation of this region is frequently seen in functional neuroimaging studies of episodic memory, parietal lesions in primates including man do not normally cause episodic memory deficits (Cabeza et al., 2008; Schoo et al., 2011). If the PPC is viewed as part of complex circuits that mediate consolidation (Izquierdo and Medina, 1997; Izquierdo et al., 1997, 2006) and retrieval (Izquierdo et al., 1997; Barros et al., 2000, 2001), the "puzzle" might be explained by the possibility that other regions of the brain take over the role of the PPC in consolidation and retrieval, or by the probability that the role of the PPC in both processes is accessory rather than central (Izquierdo et al., 1997, 2006). In rats, pharmacological inactivation (Pinto-Hamuy et al., 2004; Espina-Marchant et al., 2009) of the PPC or inhibitors of protein kinases A (Zanatta et al., 1996; Ardenghi et al., 1997; Izquierdo et al., 1997; Barros et al., 1998), protein kinase C (Bonini et al., 2005) or of extracellularly regulated kinases (ERKs), or a glutamatergic NMDA receptor blocker or a GABA-A agonist given into the PPC have strong post-training amnesic effects (Alonso et al., 2005). Post-training lesions of the PPC, unlike those produced in the hippocampus, are amnesic for idiothetic information memory in the rat (Okaichi et al., 2006). It is to be noted, however, that unlike in the hippocampus or the amygdala (Cammarota et al., 2008) in the parietal cortex these amnesic effects are obtained with delayed (i.e., $>90 \mathrm{~min}$ ) rather than with immediate post-training administrations (Zanatta et al., 1996; Izquierdo et al., 1997). This has been attributed to a delay caused by the entorhinal cortex station between hippocampus and/or amygdala and parietal cortex (Izquierdo et al., 1997, 2007); indeed the drug effects are seen when the drug treatments are given $30 \mathrm{~min}$ post-training in the entorhinal cortex (Izquierdo et al., 1997), and 90 or $180 \mathrm{~min}$ but not $0-60 \mathrm{~min}$ post-training in the PPC (Rossato et al., 2004). Treatments that stimulate protein kinases given into the PPC enhance episodic retrieval when given 90 min post-training (Ardenghi et al., 1997); so does the indirect $\mathrm{GABA}_{\mathrm{A}}$ receptor antagonist, bicuculline (Luft et al., 2004).

Thus, some of the molecular components of the role of the PPC in memory encoding or consolidation have been identified by pharmacological means; i.e., by the microinfusion of a variety of drugs into this structure bilaterally at various times in the post-training period (Ardenghi et al., 1997; Izquierdo et al., 1997; Barros et al., 1998; Schröder et al., 2000; Luft et al., 2004; Alonso et al., 2005; Bonini et al., 2005); others by measuring biochemical changes in this structure at those times (Alonso et al., 2005; Izquierdo et al., 2007). They were found to participate, as said, beginning 60-90 min post-training, i.e., 60-90 min after the participation of the hippocampus and the basolateral amygdala in consolidation, and 30 or so min after that of the entorhinal cortex (Izquierdo and Medina, 1997; Izquierdo et al., 2006).

When infused into the PPC $1 \mathrm{~h}$ after training, recombinant BDNF (brain-derived neurotrophic factor) increased, and an antibody against BDNF decreased, both short- and long-term memory of one-trial inhibitory avoidance, and pCREB/CREB levels in that structure. The effects of BDNF or its antibody did not correlate with changes in local activity of ERK1, ERK2, or PKA, which suggests they were not mediated by changes in the activity of these enzymes (Alonso et al., 2005). These results are of importance since BDNF is known to stimulate growth of recently stimulated synapses (Nagappan and Lu, 2005) and because of this has been attributed role in consolidation (Alonso et al., 2002) and post-consolidational mechanisms favoring memory persistence (Bekinschtein et al., 2007). They enhance the postulation of PPC as a brain region crucial for memory formation (Alonso et al., 2005).

It is yet not known just in what aspects or components of episodic memory formation the PPC is involved or plays a role. Bilateral damage to this area does not impair associative memory for paired stimuli, which suggests it should be involved not in the Pavlovian association but in other aspects of episodic memory (Berryhill et al., 2010a). Some studies suggest a role in the emotional component (Weymar et al., 2011), which, as is known, is at the root of memory persistence (McGaugh, 2000; Izquierdo et al., 2007) and in humans at least is widely believed to be always present to some degree. Others suggest a role in attentional components (Sestieri et al., 2011) which may be important in encoding or consolidation. In all likelihood, whatever the role, the PPC probably does not play it alone, but in association with complex circuits including the hippocampus, amygdala, entorhinal cortex (Izquierdo et al., 2007) and prefrontal regions (Sohn et al., 2005). In contrast to several other structures that are involved in consolidation, such as the hippocampus, basolateral amygdala, entorhinal, and at least parts of the prefrontal cortex [recent negative pharmacological findings suggest that the PPC is not involved in extinction] (Myskiw et al., 2010).

Kesner and associates (Chiba et al., 2002) studied two variants of a continuous recognition procedure in rats, a continuous reinforcement condition reflecting perceptual memory and a differential reinforcement condition reflecting episodiclike memory in a 12-arm radial maze. [For a discussion on what is episodic memory in rats, see (Kart-Teke et al., 2006)]. They showed a double dissociation between the parietal cortex, whose lesions impair performance in the continuous (perceptual) condition but not in the episodic-like situation, and the hippocampus whose lesions caused just the opposite. These findings are at odds with the relatively large literature from our group on the similar effects of amnesic treatments given into the hippocampus or the PPC in episodic memory measured in a one-trial avoidance task in rats. Certainly the type of task and the motivational and perceptual aspects involved could play a major role in lesion or drug effects; but the onetrial avoidance task is no doubt acquired and retrieved through episodes, and it has biochemical/electrophysiological correlates in hippocampus that are very similar to those of other aversive (Izquierdo et al., 2006; Whitlock et al., 2006) or non-aversive tasks which are clearly episodic in nature (Clarke et al., 2010) and, save for the differences in time-course, similar to those that may be described for the PPC [see above and (Izquierdo et al., 1997, 2007)]. In another study, Kesner and his coworkers suggested that whereas the hippocampus is necessary for 
metric representations, the parietal cortex would be necessary for topological representations (Goodrich-Hunsaker et al., 2005; see Kesner, 2009).

The interplay of the PPC and the main areas that underlie memory, such as the hippocampus (Izquierdo et al., 2007) involves probably a very wide variety of processes and functions mediated by relays in the entorhinal cortex and connections with other cortical and non-cortical regions (McCormick et al., 2010). Some of the interactions involve the action of hormones or other substances on both the hippocampus and the parietal cortex, of which 11-beta-hydroxysteroids like glucocorticoids may be an example: a dehydrogenase for such substances is expressed in both brain regions and increases with aging (Holmes et al., 2010). Glucocorticoids modulate a variety of memory-related processes (Schwabe and Wolf, 2011).

The participation of the PPC in memory consolidation long after the hippocampus and the basolateral amygdala have done so may represent a final, but perhaps not indispensable, "approval signature" on the whole process initiated by the hippocampus and the amygdala (Izquierdo et al., 2006).

\section{RETRIEVAL OF LONG-TERM MEMORY}

Many studies suggest that the PPC regulates retrieval and others that it is specifically in charge of recognition (Rugg and Curran, 2007; Haramati et al., 2008; Weiss et al., 2009; Winters and Reid, 2010; Weymar et al., 2011). Retrieval is supposed to englobe both recall and recognition. Many view the dichotomy between recall and recognition as flimsy [see (Olson and Berryhill, 2009)]. In many behaviors one cannot see one without the other. Even in animal tasks defined as recognition tasks (object recognition, social recognition) there must be recall prior to or together with recognition; if characteristics of the recognized object are not recalled there can be no recognition. The word "recognition" means "cognition again" or "renewed cognition"; i.e., "to know again." In order to "call again" (recall) a memory, animals must "know" what they are calling. However, there can be of course recall without recognition: animals may "remember" without really knowing what they remember.

Recognition is believed to result from two processes: recollection and familiarity (Weymar et al., 2010). Evoked potential and other studies suggest that the hippocampus and parietal cortex are involved with the former and the prefrontal cortex and amygdala are involved with the latter (Rugg and Curran, 2007; Farovik et al., 2011; Weymar et al., 2011). The recollection process can be inhibited by systemic propranolol in humans (Weymar et al., 2011) and declines with age (Friedman et al., 2010).

It has been known for a long time that retrieval is not a passive process, but rather one that requires active construction (Barros et al., 2000; Flavell et al., 2011). Several molecular events are recruited at a short notice in a number of brain areas, mostly cortical, and are required for retrieval, including recall and recognition; some of these events are similar to those of consolidation, but their time-course is compressed into a few seconds, rather than distributed over hours (Barros et al., 2000, 2001; Szapiro et al., 2000).

In any case, clearly the PPC participates in the retrieval of one-trial inhibitory avoidance. The localized bilateral infusion of the dopamine D1 agonist SKF38393, noradrenaline, the 5HT-1A antagonist NAN-190, or of the muscarinic stimulant oxotremorine into the PPC $0 \mathrm{~min}$ prior to a $24 \mathrm{~h}$ retention test session of one-trial step-down inhibitory avoidance enhances retention test performance. The localized bilateral infusion of the $\mathrm{D} 1$ antagonist $\mathrm{SCH} 23390$, of the $\beta$-noradrenergic antagonist timolol, of the 5HT-1A agonist 8-HO-DPAT (hydroxyldipropylaminotetraline) and of the muscarinic antagonist scopolamine hinders retention test performance. Three hours after the infusions, retention test performance returned to normal in all cases. None of these treatments affected locomotion or rearing in an open field or behavior in the elevated plus maze. Therefore, their effects on retention testing can be attributed to an influence on one or other or all components of retrieval. In conclusion, memory retrieval of this apparently simple task requires the participation of CA1, entorhinal, posterior parietal and anterior cingulate cortex, and is strongly modulated by, dopaminergic D1, $\beta$-noradrenergic, muscarinic cholinergic, and 5HT1A receptors in the four areas. The first three types of receptor enhance, and the latter inhibits, retrieval (Barros et al., 2001). In addition, the glutamate NMDA receptor blocker, AP5, the AMPA receptor blocker, 6,7-dinitroquinoxaline-2,3 $(1 \mathrm{H}, 4 \mathrm{H})$ dione (DNQX), and various glutamate metabotropic receptor antagonists also block retrieval when infused into the PPC (Barros et al., 2000; Szapiro et al., 2000).

Concerning the molecular mechanisms involved in retrieval beyond the receptor level in the PPC, infusion into that structure 5 min before retention testing of the ERK inhibitor PD098050, or of the inhibitor of the CAMP-dependent protein kinase (PKA), Rp-cAMPs inhibit retrieval, whereas infusion of the PKA stimulant, Sp-cAMPs enhances retrieval of the inhibitory avoidance task (Barros et al., 2000; Szapiro et al., 2000). All these drugs, at the same doses, had been previously found to alter long-term memory formation of this task.

\section{PPC AND MEMORY: OVERVIEW}

Data suggest a key role of the PPC in working memory of various types, alongside and possible in cooperation with that of the anterolateral prefrontal cortex and hippocampus, and involving different neurotransmitter combinations than those in these other structures. In addition, the PPC also plays an important and necessary role in the memory consolidation of at least one-trial inhibitory avoidance. This role is exerted 90-180 min after that of the hippocampus and basolateral amygdala, and requires more or less the same molecular processes used by these two other regions: glutamatergic transmission down regulated by $\mathrm{GABA}_{\mathrm{A}}$ synapses, and activation of the ERKS and the protein kinases $\mathrm{A}$ and $\mathrm{C}$. At the time of retrieval, the PPC is required alongside the hippocampus, basolateral amygdala, entorhinal cortex, and anterior cingulate cortex. It requires, like these other structures, unimpeded ERK and PKA function, and is regulated positively by $\beta$-noradrenergic, D1dopaminergic, and muscarinic cholinergic receptors, and down regulated by serotonin-1A synapses. Therefore, the PPC may be viewed as an important member of the neural networks that govern working memory and the formation and retrieval of episodic memory. 


\section{REFERENCES}

Alonso, M., Bekinschtein, P., Cammarota, M., Vianna, M. R., Izquierdo, I., and Medina, J. H. (2005). Endogenous BDNF is required for long-term memory formation in the rat parietal cortex. Learn. Mem. 12, 504-610.

Alonso, M., Viola, H., Izquierdo, I., and Medina, J. H. (2002). Aversive experiences are associated with a rapid and transient activation of ERKs in the rat hippocampus. Neurobiol. Learn. Mem. 77, 119-124.

Ardenghi, P., Barros, D., Izquierdo, L. A., Bevilaqua, L., Schröder, N., Quevedo, J., Rodrigues, C., Madruga, M., Medina, J. H., and Izquierdo, I. (1997). Late and prolonged post-training memory modulation in entorhinal and parietal cortex by drugs acting on the cAMP/protein kinase A signaling pathway. Behav. Pharmacol. 8, 745-751.

Aujla, H., and Beninger, R. J. (2001). Hippocampal-prefrontocortical circuits: PKA inhibition in the prefrontal cortex impairs delayed nonmatching in the radial maze in rats. Behav. Neurosci. 115, 1204-1211.

Barros, D. M., Izquierdo, L. A., Mello e Souza, T., Ardenghi, P. G., Pereira, P., Medina, J. H., and Izquierdo, I. (2000). Molecular signaling pathways in the cerebral cortex are required for retrieval of one-trial avoidance learning in rats. Behav. Brain Res. 114, 183-192.

Barros, D. M., Izquierdo, L. A., Quevedo, J., Rodrigues, C., Madruga, M., Medina, J. H., and Izquierdo, I. (1998). Interaction between midazolam-induced anterograde amnesia and memory enhancement by treatments given hours later in hippocampus, entorhinal cortex or posterior parietal cortex. Behav. Pharmacol. 92, 163-167.

Barros, D. M., Mello e Souza, T., De David, T., Choi, H., Aguzzoli, A., Madche, C., Ardenghi, P., Medina, J. H., and Izquierdo, I. (2001). Simultaneous modulation of retrieval by dopaminergic $\mathrm{D}(1)$, beta-noradrenergic, serotonergic$1 \mathrm{~A}$ and cholinergic muscarinic receptors in cortical structures of the rat. Behav. Brain Res. 124, 1-7.

Barros, D. M., Ramirez, M. R., and Izquierdo, I. (2005). Modulation of working, short- and long-term memory by nicotinic receptors in the basolateral amygdala in rats. Neurobiol. Learn. Mem. 83, 113-118.
Bekinschtein, P., Cammarota, M., Igaz, L. M., Bevilaqua, L. R. M., Izquierdo, I., and Medina, J. H. (2007). Persistence of longterm memory storage requires a late protein synthesis- and BDNF-dependent phase in the hippocampus. Neuron 53, 261-267.

Berryhill, M. E., Chein, J., and Olson, I. R. (2011). At the intersection of attention and memory: the mechanistic role of the posterior parietal lobe in working memory. Neuropsychologia 49, 1306-1315.

Berryhill, M. E., Phuong, L., Picasso, L., Cabeza, R., and Olson, I. R. (2007). Parietal lobe and episodic memory: bilateral damage causes impaired free recall of autobiographical memory. J. Neurosci. 27, 14415-14423.

Berryhill, M. E., Picasso, L., Arnold, R., Drowos, D., and Olson, I. R. (2010a). Similarities and differences between parietal and frontal patients in autobiographical and constructed experience tasks. Neuropsychologia 48, 1385-1393.

Berryhill, M. E., Wencil, E. B., Branch Coslett, H., and Olson, I. R. (2010b). A selective working memory impairment after transcranial direct current stimulation to the right parietal lobe. Neurosci. Lett. $479,312-316$

Bonini, J. S., Cammarota, M., Kerr, D. S., Bevilaqua, L. R., and Izquierdo, I. (2005). Inhibition of PKC in basolateral amygdala and posterior parietal cortex impairs consolidation of inhibitory avoidance memory. Pharmacol. Biochem. Behav. 80 63-67.

Bucci, D. J. (2009). Posterior parietal cortex: an interface between attention and learning? Neurobiol. Learn. Mem. 91, 114-120.

Buschman, T. J., and Miller, E. K. (2007). Top-down versus bottomup control of attention in the prefrontal and posterior parietal cortices. Science 315, 1860-1862.

Cabeza, R., Ciaramelli, E., Olson, I. R., and Moscovitch, M. (2008). The parietal cortex and episodic memory: an attentional account. Nat. Rev. Neurosci. 9, 613-625.

Cammarota, M., Bevilaqua, I. R., Rossato, J. I., Lima, R. H., Medina, J. H., and Izquierdo, I. (2008). Parallel memory processing by the CA1 region of the dorsal hippocampus and the basolateral amygdala. Proc. Natl. Acad. Sci. U.S.A. 105, 10279-10284.

Chafee, M. V., and Goldman-Rakic, P. S. (2000). Inactivation of parietal and prefrontal cortex reveals interdependence of neural activity during memory-guided saccades. J. Neurophysiol. 83, 1550-1566.

Chiba, A. A., Kesner, R. P., and Jackson, P. A. (2002). Two forms of spatial memory: a double dissociation between the parietal cortex and the hippocampus in the rat. Behav Neurosci. 116, 874-883.

Clarke, J. R., Cammarota, M., Gruart, A., Izquierdo, I., and DelgadoGarcía, J. M. (2010). Plastic modifications induced by object recognition memory processing. Proc. Natl. Acad. Sci. U.S.A. 107, 2652-2657.

Compton, D. M., McDaniel, W. F. and Dietrich, K. L. (1994). Nonspatial learning following posterior parietal or hippocampal lesions Neuroreport 5, 2189-2192.

Constantinidis, C. (2006). Posterior parietal mechanisms of visual attention. Rev. Neurosci. 17, 415-427.

Constantinidis, C., and Steinmetz, M. A. (1996). Neuronal activity in posterior parietal area $7 \mathrm{a}$ during the delay periods of a spatial memory task. J. Neurophysiol. 76, 1352-1355.

Curtis, C. E. (2006). Prefrontal and parietal contributions to spatial working memory. Neuroscience 139, 173-180.

Delgado-García, J. M. (2011). Lenguaje del Cerebro. Sevilla: Letra Áurea.

Delgado-García, J. M., and Gruart, A. (2006). Building new motor responses: eyelid conditioning revisited. Trends Neurosci. 29, 330-338.

Ding, S. L., Van Hoesen, G., and Rockland, K. S. (2000). Inferior parietal lobule projections to the presubiculum and neighboring ventromedial temporal cortical areas. J. Comp. Neurol. 425, 510-530.

Drowos, D. B., Berryhill, M., André, J. M., and Olson, I. R. (2010). True memory, false memory, and subjective recollection deficits after focal parietal lobe lesions. Neuropsychology 24, 465-475.

Elliott, R., and Dolan, R. J. (1998). The neural response in short-term visual recognition memory for perceptual conjunctions. Neuroimage 7 , 14-22.

Espina-Marchant, P., Pinto-Hamuy T., Bustamante, D., Morales, P. Robles, L., and Herrera-Marschitz, M. (2009). Spatial cognition and memory: a reversible lesion with lidocaine into the anteromedial/posterior parietal cortex (AM/PPC) affects differently working and long-term memory on two foraging tasks. Biol. Res. 39, 601-609.
Farovik, A., Place, R. J., Miller, D. R., and Eichenbaum, H. (2011). Amygdala lesions selectively impair familiarity in recognition memory. Nat. Neurosci. 14, 1416-1417.

Flavell, C. R., Barber, D. J., and Lee, J. L. (2011). Behavioural memory reconsolidation of food and fear memories. Nat. Commun. 2, 504.

Friedman, D., de Chastelaine, M., Nessler, D., and Malcolm, B. (2010). Changes in familiarity and recollection across the lifespan: an ERP perspective. Brain Res. 1310, 124-141.

Friedman-Hill, S. R., Robertson, L. C., Desimone, R., and Ungerleider, L. G. (2003). Posterior parietal cortex and the filtering of distractors. Proc. Natl. Acad. Sci. U.S.A. 100, 4263-4268.

Gold, P. E. (1986). The use of avoidance training in studied of modulation of memory storage. Behav. Neural Biol. 46, 87-98.

Goldman-Rakic, P. S. (1991). "Prefrontal cortical dysfunction in schizophrenia: the relevance of working memory," in Psychopathology and the Brain, ed B. J. Carroll and J. E. Barrett, (New York, NY: Raven Press), 97-112.

Goodrich-Hunsaker, N. J., Hunsaker, M. R., and Kesner, R. P. (2005). Dissociating the role of the parietal cortex and dorsal hippocampus for spatial information processing. Behav. Neurosci. 119, 1307-1315.

Haramati, S., Soroker, N., Dudai, Y. and Levy, D. A. (2008). The posterior parietal cortex in recognition memory: a neuropsychological study. Neuropsychologia 46, 1756-1766.

Holmes, M. C., Carter, R. N., Noble, J., Chitnis, S., Dutia, A., Paterson, J. M., Mullins, J. J., Seckl, J. R., and Yau, J. L. (2010). 1lbetahydroxysteroid dehydrogenase type 1 expression is increased in the aged mouse hippocampus and parietal cortex and causes memory impairments. J. Neurosci. 30, 6916-6920.

Hutchinson, J. B., Uncapher, M. R., and Wagner, A. D. (2009). Posterior parietal cortex and episodic retrieval: convergent and divergent effects of attention and memory. Learn. Mem. 16, 343-356.

Ingles, J. L., Beninger, R. J., Jhamandas, K., and Boegman, R. J. (1993). Scopolamine injected into the rat amygdala impairs working memory in the double Y-maze. Brain Res. Bull. 32, 339-344.

Izquierdo, I., Bevilaqua, L. R. M., Rossato, J. I., Bonini, J. S., Medina, J. H., and Cammarota, M. (2006). 
Different molecular cascades in different sites of the brain control consolidation. Trends Neurosci. 29, 496-505.

Izquierdo, I., Izquierdo, L. A., Barros, D. M., Mello e Souza, T., de Souza, M. M., Quevedo, J., Rodrigues, C., Kauer Sant'Anna, M., Madruga, M., and Medina, J. H. (1998). Differential involvement of cortical receptor mechanisms in working, short- and long-term memory. Behav. Pharmacol. 9, 421-427.

Izquierdo, I., and Medina, J. H. (1997). Memory formation: the sequence of biochemical events in the hippocampus and its connection to activity in other brain structures. Neurobiol. Learn. Mem. 68, 285-316.

Izquierdo, I., Quillfeldt, J. A., Zanatta, M. S., Quevedo, J., Schaeffer, E., Schmitz, P. K., and Medina, J. H. (1997). Sequential involvement of hippocampus and amygdala, entorhinal cortex and parietal cortex in the formation and expression of memory for inhibitory avoidance in rats. Eur. J. Neurosci. 9, 786-793.

Izquierdo, L. A., Barros, D. M., da Costa, J. C., Furini, C., Zinn, C., Cammarota, M., Bevilaqua, L. R., and Izquierdo, I. (2007). A link between role of two prefrontal areas in immediate memory and in long-term memory consolidation. Neurobiol. Learn. Mem. 88, 160-188.

Jacobsen, C. F. (1936). Studies of cerebral function in primates. Comp. Psychol. Monogr. 13, 1-68.

Jiménez-Díaz, L., Sancho-Bielsa, F., Gruart, A., Lopéz-García, C., and Delgado-García, J. M. (2006). Evolution of cerebral cortex involvement in the acquisition of associative learning. Behav. Neurosci. 120, 1043-1056.

Jerde, T. A., Childs, S. K., Handy, S. T., Nagode, J. C., and Pardo, J. V. (2011). Dissociable systems of working memory for rhythm and melody. Neuroimage 57, 1572-1579.

Joelving, F. C., Compte, A., and Constantinidis, C. (2007). Temporal properties of posterior parietal neuron discharges during working memory and passive viewing. J. Neurophysiol. 97, 2254-2266.

Kang, S. S., Sponheim, S. R., Chafee, M. V., and MacDonald, A. W. 3rd. (2011). Disrupted functional connectivity for controlled visual processing as a basis for impaired spatial working memory in schizophrenia. Neuropsychologia 49, 2836-2847.
Kart-Teke, E., De Souza Silva, M. A., Huston, J. P., and Dere, E. (2006). Wistar rats show episodiclike memory for unique experiences. Neurobiol. Learn. Mem. 85, 173-182.

Keene, C. S., and Bucci, D. J. (2008). Contributions of the retrosplenial and posterior parietal cortices to cue-specific and contextual fear conditioning. Behav. Neurosci. 122, 89-97.

Kesner, R. P. (2009). The posterior parietal cortex and long-term memory representation of spatial information. Learn. Mem. 91, 197-206.

Lepage, M., Pelletier, M., Achim, A., Montoya, A., Menear, M., and Lal, S. (2010). Parietal cortex and episodic memory retrieval in schizophrenia. Psychiatry Res. 182, 191-199.

Luft, T., Pereira, G. S., Cammarota, M., and Izquierdo, I. (2004). Different time course for the memory facilitating effect of bicuculline in hippocampus, entorhinal cortex, and posterior parietal cortex of rats. Neurobiol. Learn. Mem. 82 , 52-56.

McCormick, C., Moscovitch, M., Protzner, A. B., Huber, C. G. and McAndrews, M. P. (2010). Hippocampal-neocortical networks differ during encoding and retrieval of relational memory: functional and effective connectivity analyses. Neuropsychologia 48, 3272-3281.

McGaugh, J. L. (1966). Timedependent processes in memory storage. Science 153, 1351-1358.

McGaugh, J. L. (2000). Memory: a century of consolidation. Science 287, 248-251.

McVea, D. A., and Pearson, K. G. (2009). Object avoidance during locomotion. Adv. Exp. Med. Biol. 629, 293-315.

McVea, D. A., Taylor, A. J., and Pearson, K. G. (2009). Long-lasting working memories of obstacles established by foreleg stepping in walking cats require area 5 of the posterior parietal cortex. J. Neurosci. 29, 9396-9404.

Myskiw, J. C., Fiorenza, N. G. Izquierdo, L. A., and Izquierdo, I. (2010). Molecular mechanisms in hippocampus and basolateral amygdala but not in parietal or cingulate cortex are involved in extinction of one-trial avoidance learning. Neurobiol. Learn. Mem. 94, 285-291.

Nagappan, G., and Lu, B. (2005). Activity-dependent modulation of the BDNF receptor TrkB: mechanisms and implications. Trends Neurosci. 28, 464-471.
Okaichi, H., Hojo, M., and Okaichi, Y. (2006). Effects of post-training lesions in the hippocampus and the parietal cortex on idiothetic information processing in the rat. Rev Neurosci. 17, 135-146.

Olson, I. R., and Berryhill, M. (2009). Some surprising findings on the involvement of the parietal lobe in human memory. Neurobiol. Learn. Mem. 91, 155-165.

Otsuka, Y., Osaka, N., and Osaka, M. (2008). Functional asymmetry of superior parietal lobule for working memory in the elderly. Neuroreport 19, 1355-1359.

Pinto-Hamuy, T., Montero, V. M., and Torrealba, F. (2004). Neurotoxic lesion of anteromedial/posterior parietal cortex disrupts spatial maze memory in blind rats. Behav. Brain Res. 153, 465-470.

Quintana, J., and Fuster, J. M. (1999) From perception to action: temporal integrative functions of prefrontal and parietal neurons. Cereb. Cortex 9, 213-221.

Rawley, J. B., and Constantinidis, C. (2009). Neural correlates of learning and working memory in the primate posterior parietal cortex. Neurobiol. Learn. Mem. 91, 129-138.

Reep, R. L., and Corwin, J. V. (2009). Posterior parietal cortex as part of a neural network for directed attention in rats. Neurobiol. Learn. Mem. 91, 104-113.

Richmond, L. L., Morrison, A. B., Chein, J. M., and Olson, I. R. (2011). Working memory training and transfer in older adults. Psychol Aging 26, 813-822.

Rogers, J. L., and Kesner, R. P. (2007) Hippocampal-parietal cortex interactions: evidence from a disconnection study in the rat. Behav. Brain Res. 179, 19-27.

Rossato, J. I., Bonini, J. S., Cammarota, M., Medina, J. H., and Izquierdo, I. (2004). Retrograde amnesia induced by drugs acting on different molecular systems. Behav Neurosci. 118, 563-568.

Rugg, M. D., and Curran, T. (2007) Event-related potentials and recognition memory. Trends Cogn. Sci. 11, 251-257.

Schoo, L. A., van Zandvoort, M J., Biessels, G. J., Kappelle, L. J., Postma, A., and de Haan, E. H. (2011). The posterior parietal paradox: why do functional magnetic resonance imaging and lesion studies on episodic memory produce conflicting results? J. Neuropsychol. 5, 15-38.

Schröder, N., de-Paris, F., Roesler, R., Medina, J. H., Souza, D. O. and Izquierdo, I. (2000). Effect of inhibtory avoidance training on $3 \mathrm{H}-$ glutamate binding in the hippocampus and parietal cortex of rats. Braz. J. Med. Biol. Res. 33, 229-232.

Schwabe, L., and Wolf, O. T. (2011). Stress-induced modulation of instrumental behavior: from goaldirected to habitual control of action. Behav. Brain Res. 219, 321-328.

Sestieri, C., Corbetta, M., Romani, G. L., and Shulman, G. L. (2011) Episodic memory retrieval, parietal cortex, and the default mode network: functional and topographic analyses. J. Neurosci. 31, 4407-4420.

Sohn, M. H., Goode, A., Stenger, V. A., Jung, K. J., Carter, C. S., and Anderson, J. R. (2005). An information-processing model of three cortical regions: evidence in episodic memory retrieval. Neuroimage 25, 21-33.

Szapiro, G., Izquierdo, L. A., Alonso, M., Barros, D., Paratcha, G., Ardenghi, P., Pereira, P., Medina, J. H., and Izquierdo, I. (2000). Participation of hippocampal metabotropic glutamate receptors, protein kinase $\mathrm{A}$ and mitogenactivated protein kinases in memory retrieval. Neuroscience 99, 1-5.

Weiss, A. P., Ellis, C. B., Roffman, J. L., Stufflebeam, S., Hamalainen, M. S. Duff, M., Goff, D. C., and Schacter D. L. (2009). Aberrant frontoparietal function during recognition memory in schizophrenia: a multimodal neuroimaging investigation. J. Neurosci. 29, 11347-11359.

Weymar, M., Löw, A., and Hamm, A. O. (2011). Emotional memories are resilient to time: evidence from the parietal ERP old/new effect. Hum. Brain Mapp. 32, 632-640.

Weymar, M., Löw, A., Modess, C., Engel, G., Gründling, M., Petersmann, A., Siegmund, W., and Hamm, A. O. (2010). Propranolol selectively blocks the enhanced parietal old/new effect during longterm recollection of unpleasant pictures: a high density ERP study. Neuroimage 49, 2800-2806.

Whitlock, J. R., Heynen, A. J., Shuler, M. G., and Bear, M. F. (2006). Learning induces long-term potentiation in the hippocampus. Science 313, 1093-1097.

Whitlock, J. R., Sutherland, R. J., Witter, M. P., Moser, M. B., and Moser, E. I. (2008). Navigating from hippocampus to parietal cortex. Proc. Natl. Acad. Sci. U.S.A. 105, 14755-14762.

Winters, B. D., and Reid, J. M. (2010). A distributed cortical representation underlies crossmodal object 
recognition in rats. J. Neurosci. 30, 6253-6261.

Zanatta, M. S., Schaeffer, E., Schmitz, P. K., Medina, J. H., Quevedo, J., Quillfeldt, J. A., and Izquierdo, I. (1996). Sequential involvement of NMDA-dependent mechanisms in hippocampus, amygdala, entorhinal cortex and parietal cortex in memory processing. Behav. Pharmacol. 7, 341-345.

Conflict of Interest Statement: The authors declare that the research was conducted in the absence of any commercial or financial relationships that could be construed as a potential conflict of interest.
Received: 16 January 2012; accepted: 14 February 2012; published online: 27 February 2012.

Citation: Myskiw JC and Izquierdo I (2012) Posterior parietal cortex and long-term memory: some data from laboratory animals. Front. Integr. Neurosci. 6:8. doi: 10.3389/fnint. 2012.00008
Copyright (C) 2012 Myskiw and Izquierdo. This is an open-access article distributed under the terms of the Creative Commons Attribution Non Commercial License, which permits non-commercial use, distribution, and reproduction in other forums, provided the original authors and source are credited. 